\title{
Evaluation of doctors' performance as facilitators in basic medical science lecture classes in a new Malaysian medical school
}

This article was published in the following Dove Press journal:

Advances in Medical Education and Practice

3I March 2015

Number of times this article has been viewed

\author{
Salwani Ismail' \\ Abdus Salam² \\ Ahmed G Alattraqchi' \\ Lakshmi Annamalai' \\ Annamalai Chockalingam' \\ Wan Putri Elena ${ }^{3}$ \\ Nor Iza A Rahman' \\ Abdullahi Rabiu Abubakar' \\ Mainul Haque' \\ 'Faculty of Medicine, Universiti Sultan \\ Zainal Abidin, Kuala Terengganu, \\ Terengganu, Malaysia; ${ }^{2}$ Department of \\ Medical Education, Universiti Kebangsaan \\ Malaysia Medical Centre, Kuala Lumpur, \\ Malaysia; ${ }^{3}$ School of Health Sciences, \\ Health Campus, Universiti Sains Malaysia, \\ Kubang Kerian, Kelantan, Malaysia
}

\section{Video abstract}

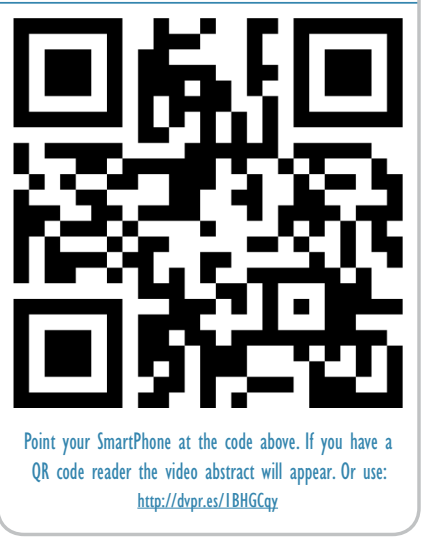

Correspondence: Mainul Haque Unit of Pharmacology, Faculty of Medicine, Universiti Sultan Zainal Abidin, Kampus Kota, Jalan Sultan Mahmud, 20400 Kuala Terengganu, Terengganu, Malaysia

Tel +6096275674

Fax +6096275639

Email runurono@gmail.com
Background: Didactic lecture is the oldest and most commonly used method of teaching. In addition, it is considered one of the most efficient ways to disseminate theories, ideas, and facts. Many critics feel that lectures are an obsolete method to use when students need to perform hands-on activities, which is an everyday need in the study of medicine. This study evaluates students' perceptions regarding lecture quality in a new medical school.

Methods: This was a cross-sectional study conducted of the medical students of Universiti Sultan Zainal Abidin. The study population was 468 preclinical medical students from years 1 and 2 of academic year 2012-2013. Data were collected using a validated instrument. There were six different sections of questions using a 5-point Likert scale. The data were then compiled and analyzed, using SPSS version 20.

Results: The response rate was $73 \%$. Among 341 respondents, $30 \%$ were male and $70 \%$ were female. Eighty-five percent of respondents agree or strongly agree that the lectures had met the criteria with regard to organization of lecture materials. Similarly, $97 \%$ of students agree or strongly agree that lecturers maintained adequate voices and gestures.

Conclusion: Medical students are quite satisfied with the lecture classes and the lectures. However, further research is required to identify student-centered teaching and learning methods to promote active learning.

Keywords: lecture, effectiveness, evaluation, undergraduate medical education, Malaysia

\section{Introduction}

Attaining student satisfaction is a major aim of lecturing as a medium of instruction in all institutions of higher learning, especially medical schools. ${ }^{1}$ Attending an institution that cannot provide an effective means of teaching and learning will definitely affect students' academic performance and the school's reputation, as well as students' intake in the near future. ${ }^{1}$ Lectures as a medium of instruction consist of various aspects, including knowledge of the course, clarity of presentation, interaction with students, teaching creativity, clarifying outcome, and class activity, as well as satisfactory lecture notes. ${ }^{1}$ Although sometimes learning can take place without the benefit of teaching, there is no such thing as effective teaching in the absence of learning. Assessment of students in a classroom is very significant: It focuses on evaluating the students' understanding of the lecture, based on the intention of the lecturer. ${ }^{2}$ The major challenge in any medical school is that the lecturer needs to deliver an enormous amount of information within a short period of time, and the students are expected to understand and memorize what they were taught throughout their career. ${ }^{3}$ Therefore, it is necessary for medical schools to keep upgrading their teaching and learning curriculum, tailored 
toward student-centered learning, team-based learning, and problem-based learning, as well as use an interactive lecture class system. ${ }^{3}$

Lectures as a medium of instruction, if properly coordinated by an experienced lecturer, will yield a noteworthy outcome. Teaching and learning are two facets of the academic world, and both depend on the instructor's ability. A professional and effective lecturer is the one who can pass the knowledge to the students effectively, achieving the desired outcome of learning by the students who attended the lecture. ${ }^{1}$ A good lecturer must perform a variety of tasks in the process of teaching, such as providing the course outline, assessing the students, and giving them feedback. In addition, they must encourage, motivate, and assist the students in achieving the desired goal. ${ }^{4}$ Interaction and exchange of information between the lecturer and the students is very important: It helps in building students knowledge and motivation of students and improves social relationships. ${ }^{5}$

Lecturing as a medium of instruction has undergone several criticisms because it is a passive process, but it has managed to stay alive in many reputed universities. ${ }^{6-8}$ Lecturers need to present new information and ideas to make the learning thought-provoking. A teacher begins with an introduction, followed by a summary of the topic, which stimulates further learning. ${ }^{9}$ According to the research, good lecturers remain popular over the years for the following reasons: they are competent, dedicated, and responsive and can be acquainted with every situation, against all odds, in the classroom. ${ }^{10}$ For this reason, lectures have remained the most popular and easiest form of teaching compared with other mediums of instruction.

\section{Definition of lecture}

The term lecture derives from the Latin word legō, meaning "I recite." Therefore, lecturing involves the oral presentation of facts and figures, with the aid of slides or a blackboard, to a large group of learners. ${ }^{6,8}$ There are different types of lecture methods, as described by different scientists. ${ }^{8,11-13}$ Types of lectures include formal oral essay, expository lecture, provocative lecture, lecture discussion, lecture-recitation, lecture laboratory, lecture discussion cycle, interactive lecture, illustrated lecture, lecture cum buzz session, and so forth.

A complete lecture is expected to have some strengths, weaknesses, and applications.

\section{Strength}

Lecturing is a competent way of conveying facts; good lecturers familiarize themselves with the topic and analyze the students' perception and approach through text-, web-, or field-based activities. ${ }^{14}$

\section{Weaknesses}

Lecturing is not as good as a small group session when it comes to stimulating thinking and inspiring interest in a subject, and behavioral skills and attitudes, such as asking silly questions, may not be possible, which is normal in a small group session. ${ }^{14}$ It is important to note that lectures are only part of the learning cycle: the students still have to assimilate the content for deep learning.

\section{Applications}

The majority of lecturers believe "lectures are necessary but should be limited in capacity and well presented. Students need to apply the lecture into a real-life situation and relate with their previous knowledge."14

Various institutions of learning have discovered the disadvantages of lecture classes. Lecture classes are usually boring and also can be stressful on many occasions. ${ }^{1}$ Other instruction mediums are gaining popularity and are used in many universities, including medical schools. They can be used exclusively or in support of lecture classes and include problem-based learning, team-based learning, peer-led workshops, and online instruction. ${ }^{15-18}$ The competency of a lecturer is of paramount importance because it determines the success or failure of the lecture class. Three major aspects that determine the lecturer's competency include knowledge, attitude, and skills. ${ }^{1}$ Similarly, in another definition, lecturer competency depends on the teaching and learning environment, the culture and values held in that community, and students' attitudes toward learning. ${ }^{1}$ To appreciate the merits and demerits of lecture classes, the alternative media of instruction mentioned here need to be described further.

\section{Research objectives}

The objectives of our research were to assess the organization of the materials used in lecture classes, to evaluate the voices and gestures used in delivering the lectures, to assess the efficiency of visual aids and resources, to evaluate the fulfillment of lecture class objectives, and to assess the quality of the lecture venue.

\section{Materials and methods}

This was a cross-sectional study conducted on medical students from Universiti Sultan Zainal Abidin. The study population was 468 preclinical medical students from years 1 and 2 
of academic year 2012-2013. A universal sampling method was used to cover all preclinical students. The period of study was March-May 2013. The questionnaire was adopted, modified, and validated from the previous study. ${ }^{19}$ The questionnaire consists of six different sections on a 5-point Likert scale. The first five sections contained 28 questions and five options to choose from and circle. The sixth section contained one closed and two open-ended questions. The questionnaires are provided in the Supplementary material (Figure S1). This study was anonymous, participation was voluntary, and verbal consent was taken. The study was approved by the Preclinical Studies, Faculty of Medicine and Health Sciences, Universiti Sultan Zainal Abidin, Kuala Terengganu, Malaysia. The questionnaires were distributed to the students during a lecture class. The data were then compiled and analyzed, using SPSS version 20. Most of the sections of this questionnaire demonstrated acceptable values, with a range between 0.672 and 0.882 , which indicated that both instruments possessed good internal consistency and reliability. The evidence of convergent validity was shown by the significant correlations between the items of each section and the total mean in each section $\left(r_{s}=0.332-0.718 ; P<0.05\right){ }^{20,21}$

\section{Results}

Of 468 students, 341 responded, giving a response rate of $73 \%$. The demographic data of the study participants are described in Table 1.

\section{Regarding organization of lecture materials}

The maximum score of the questions regarding the organization of lecture materials (ROLM) was 45. Eighty-five percent (292) of the current study population either strongly agreed (SA) or agreed (A) that lectures had met the criteria. The remaining $15 \%$ (49) of the students either strongly disagreed (SD), disagreed (D), or were undecided (U). The mean score for male students was $38.76 \pm 4.53$, and for females it was $38.99 \pm 4.39$. There was no statistically significant $(P=0.665)$ difference between sexes. There were statistically significant

Table I Demographic data of study populations

\begin{tabular}{ll}
\hline Items & $\begin{array}{l}\text { Frequency, } \\
\mathbf{n}(\%)\end{array}$ \\
\hline $\begin{array}{l}\text { Year I } \\
\text { Male }\end{array}$ & $60(31)$ \\
Female & $137(69)$ \\
Year 2 & \\
Male & $42(29)$ \\
Female & $102(71)$ \\
\hline
\end{tabular}

differences $(P=0.041)$ in the mean score for ROLM between year $1(39.36 \pm 4.05)$ and year $2(38.33 \pm 4.85)$ students (Tables 2 and 3).

\section{Regarding lecture voice and gesture}

The maximum score for questions regarding lecture voice and gesture (RLVG) was 20. Three hundred thirty-two (97\%) of our respondents SA and A that lecturers used a microphone effectively. The remaining $9(3 \%)$ of students either SD or D. Although 97\% students either SA or A that lecturers effectively used the microphone, they further clarified that some lecturers were still too quiet $3(1 \%)$, were quiet $29(8 \%)$, were all right 253 (74\%), were loud, or were too loud 56 (17\%). Regarding the pace of the lecture, 278 (81\%) of our respondents agreed it was satisfactory. Nevertheless, 40 (12\%) students rated the pace as either too fast or fast. The remaining $23(7 \%)$ said it was slow or too slow. Two hundred ninetytwo $(86 \%)$ students either SA or A that the lecturers varied their rate, pitch, and force of voice for emphasis and used eye contact and body language purposefully. Nonetheless, 15 (4\%) students either D or SD that lecturers were using such skills in the class. The remainder, 34 (10\%) students, were $\mathrm{U}$. The mean scores according to sex and year of study were male, 17.16 \pm 2.44 , and female, 16.88 \pm 2.53 ; and year 1 , $17.55 \pm 1.91$, and year $2,16.15 \pm 2.96$. The mean scores were not statistically significant between the sexes $(P=0.348)$, but highly significant differences were observed in year of study $(P=0.001)$ (Tables 2 and 3$)$.

\section{Regarding use of visual aids/ resources}

The maximum score for questions regarding use of visual aids/ resources (RUVAR) was 15 . Three hundred forty (99\%) of the participants SA and A that the lecturers used visual aids and

Table 2 Average Likert scale scores (mean \pm SD; $n=34$ I) among male and female participants

\begin{tabular}{|c|c|c|c|c|c|c|}
\hline \multirow[t]{2}{*}{ Variables } & \multirow[t]{2}{*}{$\begin{array}{l}\text { Maximum } \\
\text { scores }\end{array}$} & \multicolumn{2}{|c|}{$\begin{array}{l}\text { Male } \\
(n=102)\end{array}$} & \multicolumn{2}{|c|}{$\begin{array}{l}\text { Female } \\
(n=239)\end{array}$} & \multirow[t]{2}{*}{$P$ value* } \\
\hline & & Mean & SD & Mean & SD & \\
\hline ROLM & 45 & 38.76 & 4.53 & 38.99 & 4.39 & 0.665 \\
\hline RLVG & 20 & 17.16 & 2.44 & 16.88 & 2.53 & 0.348 \\
\hline RUVAR & 15 & 13.24 & 1.52 & 13.39 & 1.50 & 0.389 \\
\hline RFOLC & 35 & 29.42 & 3.77 & 28.94 & 3.65 & 0.272 \\
\hline RPFLH & 5 & 3.89 & 1.13 & 3.90 & 0.89 & 0.949 \\
\hline
\end{tabular}

Note: *Independent $t$-test.

Abbreviations: ROLM, regarding the organization of lecture materials; RLVG, regarding lecture voice and gesture; RUVAR, regarding use of visual aids/resources; RFOLC, regarding fulfilling of the objectives of lecture class; RPFLH, regarding physical facilities of lecture hall; SD, standard deviation. 
Table 3 Average Likert scale scores (mean \pm SD; $n=34$ I) among year I and year 2 students

\begin{tabular}{|c|c|c|c|c|c|c|}
\hline \multirow[t]{2}{*}{ Variables } & \multirow[t]{2}{*}{$\begin{array}{l}\text { Maximum } \\
\text { scores }\end{array}$} & \multicolumn{2}{|c|}{$\begin{array}{l}\text { Year I } \\
(n=197)\end{array}$} & \multicolumn{2}{|c|}{$\begin{array}{l}\text { Year } 2 \\
(n=\mid 44)\end{array}$} & \multirow[t]{2}{*}{$P$ value* } \\
\hline & & Mean & SD & Mean & SD & \\
\hline ROLM & 45 & 39.36 & 4.05 & 38.33 & 4.85 & 0.041 \\
\hline RLVG & 20 & 17.55 & 1.91 & 16.15 & 2.96 & 0.001 \\
\hline RUVAR & 15 & 13.43 & 1.43 & 13.22 & 1.60 & 0.206 \\
\hline RFOLC & 35 & 29.66 & 3.50 & 28.30 & 3.80 & 0.001 \\
\hline RPFLH & 5 & 4.02 & 1.00 & 3.73 & 0.90 & 0.005 \\
\hline
\end{tabular}

Note: *Independent $t$-test.

Abbreviations: ROLM, regarding the organization of lecture materials; RLVG, regarding lecture voice and gesture; RUVAR, regarding use of visual aids/resources; RFOLC, regarding fulfilling of the objectives of lecture class; RPFLH, regarding physical facilities of lecture hall; SD, standard deviation.

that they actually enhanced the understanding of the lecture topic. Only one student possessed a negative opinion. Research participants described that Universiti Sultan Zainal Abidin lecturers were using Microsoft PowerPoint and a projector. The mean scores according to the sex and year of study were male, 13.24 \pm 1.52 and female, $13.39 \pm 1.50$; and year $1,13.43 \pm 1.43$, and year $2,13.22 \pm 1.60$. There were no statistically significant differences in scores between sexes $(P=0.389)$ and year of study ( $P=0.206)$. Again, 327 (96\%) of our students SA or A that visual aids were clear and easy to read and were coordinated with the verbal presentation and SA or A hand notes were helpful for learning the topic. Of the remainder, $3(1 \%)$ students responded as $\mathrm{D}$, and 11 were (3\%) U (Tables 2 and 3).

\section{Regarding fulfilling of the objectives of lecture class}

The maximum score for questions regarding fulfilling of the objectives of lecture class (RFOLC) was 35 . The mean scores for males (29.42 \pm 3.77$)$ and females $(28.94 \pm 3.65)$ were statistically not significant $(P=0.272)$. However, the mean score for year $1(29.66 \pm 3.50)$ and year $2(28.30 \pm 3.80)$ had a highly statistically significant difference $(P=0.001)$. Two hundred ninety-three (86\%) students either SA or A that their lecturers met the objectives of the lecture class. However, $20(6 \%)$ students either SD or D that objectives were met in the class, and the rest $28(8 \%)$ were $\mathrm{U}$ (Tables 2 and 3 ).

\section{Regarding physical facilities of lecture hall}

The maximum score for questions regarding physical facilities of lecture hall (RPFLH) was 5. There was no statistically significant difference $(P=0.949)$ in the mean score between males (3.89 \pm 1.13$)$ and females (3.90 \pm 0.89$)$. Similarly, the mean scores for year $1(4.02 \pm 1.00)$ and year $2(3.73 \pm 0.90)$ were statistically significantly different $(P=0.005)$. Two hundred fifty-three (74\%) current study participants either SA or A that physical facilities of the lecture hall were adequate; nevertheless, 31 (9\%) either SD or D, and the rest, 57 (17\%) students, were $\mathrm{U}$ (Tables 2 and 3 ).

There were no statistically significant differences between the four lectures in issues of $\operatorname{ROLM}(P=0.440), \operatorname{RLVG}(P=0.268)$, $\operatorname{RUVAR}(P=0.144)$, and $\operatorname{RPFLH}(P=0.073)$. However, there was a statistically significant difference observed in RFOLC $(0.045)$ among lectures (Table 4). Of the current study participants, only $70(21 \%)$ think that the topic delivered as a lecture class can be discussed better in some other method. Although the majority (271 [79\%]) of the participants feel the lecture was the best method for this topic, only 24 (7\%) of 341 students suggested methods that can be adapted to improve the quality of the teaching and learning. Suggested methods are using videos, using a whiteboard, providing take-home tasks, and changing the language of delivery (Table 5). Only 8 (2\%) students recommend methods for overall improvement of the quality of the lecture classes. Those recommendations were using videos, using a whiteboard, optimizing the slide presentation, and improving interaction (Table 6).

\section{Discussion}

The response rate of the students for the current study was $73 \%$, which is very similar to that of a Danish study. ${ }^{22}$ In the present study, female medical students were outnumbered

Table 4 Average Likert scale scores (mean \pm SD; $n=34$ ) among four different lecturers

\begin{tabular}{|c|c|c|c|c|c|c|c|c|c|c|}
\hline \multirow[t]{2}{*}{ Domain } & \multirow{2}{*}{$\begin{array}{l}\text { Maximum } \\
\text { scores }\end{array}$} & \multicolumn{2}{|c|}{$A(n=|| 2)$} & \multicolumn{2}{|c|}{ B $(n=87)$} & \multicolumn{2}{|c|}{$C(n=94)$} & \multicolumn{2}{|c|}{$D(n=48)$} & \multirow[t]{2}{*}{$P$ value* } \\
\hline & & Mean & SD & Mean & SD & Mean & SD & Mean & SD & \\
\hline ROLM & 45 & 39.54 & 3.56 & 41.70 & 3.64 & 35.59 & 4.11 & 38.98 & 4.10 & 0.440 \\
\hline RLVG & 20 & 16.91 & 2.42 & 18.25 & 2.04 & 15.30 & 2.38 & 18.00 & 1.74 & 0.268 \\
\hline RUVAR & 15 & 13.35 & 1.26 & 14.10 & 1.36 & 12.63 & 1.56 & 13.35 & 1.55 & 0.144 \\
\hline RFOLC & 35 & 29.37 & 3.60 & 30.85 & 3.40 & 26.86 & 3.11 & 29.58 & 3.37 & 0.045 (A vs $B)$ \\
\hline RPFLH & 5 & 4.35 & 0.84 & 3.76 & 0.98 & 3.67 & 0.87 & 3.54 & 1.09 & 0.073 \\
\hline
\end{tabular}

Note: *One-way ANOVA.

Abbreviations: ROLM, regarding the organization of lecture materials; RLVG, regarding lecture voice and gesture; RUVAR, regarding use of visual aids/resources; RFOLC, regarding fulfilling of the objectives of lecture class; RPFLH, regarding physical facilities of lecture hall; SD, standard deviation. 
Table 5 Suggested methods for improving teaching of the present topic ( $n=24$ of 34 I)

\begin{tabular}{llll}
\hline Item & Male (\%) & Female (\%) & All (\%) \\
\hline Video & $2(2)$ & $4(1.7)$ & $6(1.8)$ \\
Whiteboard & $2(2)$ & $10(4.2)$ & $12(3.5)$ \\
Take-home task & 0 & $1(0.4)$ & $1(0.3)$ \\
Language delivery & 0 & $2(0.8)$ & $2(0.6)$ \\
Diagram & $5(2)$ & $1(0.4)$ & $3(0.9)$ \\
No answers & $96(94)$ & $22 I(92.5)$ & $317(93.0)$ \\
\hline
\end{tabular}

by their male counterparts. This finding is similar to that of a number of studies in many other countries. ${ }^{3,23-25}$ Eighty-six percent of our study participants responded that lecturers clarified the objectives at the beginning of the class. This finding is similar to one from the University of California. ${ }^{26}$ Although this study compares the mean scores between sexes, there was no statistically significant difference (Table 2). This may be a result of the students' very similar cultures and ethnic origins. In contrast, there were significant differences observed in all domains excluding RLVG and RFOLC when compared between years of study (Table 3 ). This can be explained by, as they have greater maturity and more understanding of the medical schooling system, year 2 students scoring lower than year 1 students. Similarly, there were no significant statistical differences observed between lectures, with the exception of one (Table 4). This is may be a result of a well-controlled curriculum and very proper monitoring. An almost similar observation was also reported from a Bangladeshi study: that there were no statistically significant differences observed in sex and year of study. ${ }^{19}$

The findings regarding organization of lecture class are on par with the suggestions made by educational bodies and scientists. ${ }^{27}$ The bulk (97\%) of the study members also agree that lecturers used their voices and gestures effectively. Thus, our results were similar to the reports of many other educational scientists. ${ }^{19,27,28}$ Our respondents also agree that facilitators were using audiovisual aids effectively, such as slides. Therefore, the current study supports earlier research findings. ${ }^{19,29-31}$

Table 6 Students' suggestions to improve lecture class quality $(\mathrm{n}=8$ of $34 \mathrm{l})$

\begin{tabular}{llll}
\hline Item & Male (\%) & Female (\%) & All (\%) \\
\hline Video & 0 & $\mathrm{I}(0.4)$ & $\mathrm{I}(0.3)$ \\
Whiteboard & 0 & $\mathrm{I}(0.4)$ & $\mathrm{I}(0.3)$ \\
$\begin{array}{l}\text { Optimize the slide } \\
\text { presentation }\end{array}$ & $2(2.0)$ & $2(0.8)$ & $4(\mathrm{I} .2)$ \\
Interaction & $2(2.0)$ & 0 & \\
No answers & $98(96.1)$ & $235(98.3)$ & $333(97.7)$ \\
\hline
\end{tabular}

Eighty-six percent of research contributors agreed that their facilitators met the learning objectives within the lecture. Thus, the current study findings were similar to the work and advice of other educational experts. ${ }^{19,32,33}$

The quality of the lecture classes, and especially the physical facilities, also influences the learning process. Seventy-four percent of our study participants agreed that their lecture class physical facilities were adequate.

Finally, our study participants suggested interactive sessions would improve the quality of lecture classes. This finding is similar to that of a number of other studies. ${ }^{3,19,34,35}$

This is a cross-sectional study with its own integral constraints. The current study has found many positive things about the quality of lecture classes, and our students also decided that lecture classes are the most satisfactory and helpful method of teaching. ${ }^{3}$ Therefore, it can be deduced that Universiti Sultan Zainal Abidin lecturers were maintaining a high standard of instruction.

\section{Conclusion}

The medical student participants were quite satisfied with the existing lecture-dominated curriculum. It seems that our preclinical students were also happy with the current quality of the lectures. Lecture is still the major method of teaching in medical schools and many other disciplines globally, as it is the most cost-effective form of instruction. More studies evaluating students' acceptance of and the efficiency of lectures compared with newer modes of teaching are necessary, and further research is required to identify student-centered teaching and learning methods to promote active learning.

\section{Acknowledgment}

We are grateful to those medical students who participated in the study.

\section{Disclosure}

The authors report no conflicts of interest in this work.

\section{References}

1. Long CS, Ibrahim Z, Kowang TO. An analysis on the relationship between lecturers' competencies and students' satisfaction. Int Education Stud. 2014;7(1):37-46.

2. Angelo TA, Cross KP. Classroom Assessment Techniques: A Handbook for College Teachers. 2nd ed. San Francisco: Jossey-Bass; 1993.

3. Ismail S, Rahman NIA, Mohamad N, et al. Preference of teaching and learning methods in a new medical school of Malaysia. J Appl Pharm Sci. 2014;4(2):048-055.

4. Brophy J. Generic Aspects of Effective Teaching. In: Wang MC, Walberg HJ, editors. Tomorrow's Teachers. Richmond, CA: McCutchan Publishing; 2001. 
5. Johnson RD, Hornik S, Salas E. An empirical examination of factors contributing to the creation of successful e-learning environments. Int J Hum Comput Stud. 2008;66(5):356-369.

6. Brown G. Lectures and lecturing. In: Dunkin W, editor. The International Encyclopedia of Teaching and Teacher Education. Oxford: Pergamon Press; 1987.

7. Huerta JC. Getting active in the large lecture. J Polit Sci Educ. 2007; 3(3):237-249.

8. Kaur G. Study and analysis of lecture model of teaching. Int $J$ Educational Planning Admin. 2011;1(1):9-13.

9. Perrott E. Effective Teaching: A Practical Guide to Improving Your Teaching. New York: Routledge; 2014.

10. Kauchak DP, Eggen PD. Learning and Teaching: Research-Based Methods. 6th ed. Boston, MA: Pearson Education Inc.; 2012.

11. Lowman J. Mastering the Techniques of Teaching. Lahore: Ferozsons; 1987.

12. Kumar S. An innovative method to enhance interaction during lecture sessions. Adv Physiol Educ. 2003;27(1):20-25.

13. Lieux EM. A comparative study of learning in lecture vs problembased format. About Teaching. Newark: University of Delaware; 1997. Available from: http://www.udel.edu/pbl/cte/spr96-nutr. html. Accessed January 27, 2015.

14. Tyler I, Rowlands M, Spasoff R. An environmental scan of best practices in public health undergraduate medical education: strengths, weaknesses and applicability of teaching methods. J Assoc Faculties Med Can. 2009;(5):2-14.

15. Lim WK. Dysfunctional problem-based learning curricula: resolving the problem. BMC Med Educ. 2012;12:89.

16. Allen RE, Copeland J, Franks AS, et al. Team-based learning in US colleges and schools of pharmacy. Am J Pharm Educ. 2013;77(6):115.

17. Preszler RW. Replacing lecture with peer-led workshops improves student learning. CBE Life Sci Educ. 2009;8(3):182-192.

18. Cheah PK, Kok JK, Chew WL. A qualitative inquiry of online instruction among teachers in Malaysian universities and colleges. Int Je-Educ e-Bus e-Manag Learn. 2012;2(2):135-139.

19. Islam MZ, Salam A, Mosaddek ASM, et al. Appraisal of quality of pharmacology lecture class of MBBS programme in four private medical school of Bangladesh. Int Med J. 2015; 22(6): In press.

20. Nunnally JC. Psychometric Theory. 2nd ed. New York: McGraw-Hill; 1978.

21. Barman MP, Hazarika J, Kalita A. Reliability and validity of Assamese version of EORTC QLQ-C30 Questionnaire for Studying the Quality of Life of Cancer Patients of Assam. World Appl Sci J. 2012;17(5):672-678.
22. Kongsved SM, Basnov M, Holm-Christensen K, Hjollund NH. Response rate and completeness of questionnaires: a randomized study of Internet versus paper-and-pencil versions. J Med Internet Res. 2007;9(3):e25.

23. Chen MK, Chevalier JA. Are women overinvesting in education? Evidence from the medical profession. J Hum Cap. 2012;6(2):124-149.

24. BBC. Women docs "weakening" medicine. 2004. Available from: http://news.bbc.co.uk/1/hi/health/3527184.stm. Accessed October 27, 2014.

25. Elston MA. Women and medicine: the future. Royal College of Physicians; 2009. Available from: https://www.rcplondon.ac.uk/sites/default/ files/documents/women-and-medicine-future-full-report.pdf. Accessed October 27, 2014

26. Centre for Teaching and Learning. Ways to make your teaching more effective. University of California, Berkeley. Available from: http:// teaching.berkeley.edu/ways-make-your-teaching-more-effective. Accessed September 5, 2013.

27. Brown G, Manogue M. AMEE Medical Education Guide No 22: Refreshing lecturing: a guide for lecturers. Med Teach. 2001;23(3): 231-244.

28. Cheng DS, Salamin H, Salvagnini P, Cristani M, Vinciarelli A, Murino V. Predicting online lecture ratings based on gesturing and vocal behavior. J Multimodal User Interfaces. 2014;8(2):151-160.

29. Kumar A, Singh R, Mohan L, Kumar MK. Students' views on audio visual aids used during didactic lectures in a medical college. Asian J Med Sci. 2013;4(2):36-40.

30. Shridevi AS, Patil GL, Arif NK, Rashmi AG, Satvik, Shashikala P. Role of audiovisual aid as a teaching - learning method for understanding mechanism of labour. J Pub Health Med Res. 2013;1(2):97-99.

31. Chaudhary R, Dullo P, Gupta U. Attitude of 1 st MBBS medical students about two different visual aids in physiology lectures. Pak J Physiol. 2009;5(2):16-19.

32. Svinicki MD, McKeachie WJ. Mckeachie's Teaching Tips: Strategies, Research, and Theory for College and University Teachers.14th ed. Betmont, CA: Wadsworth.

33. Jisc. Designing Spaces for Effective Learning. A guide to 21 st century learning space design. 2006. Available from: http:/www.webarchive. org.uk/wayback/archive/20140616001949/http://www.jisc.ac.uk/media/ documents/publications/learningspaces.pdf. Accessed June 11, 2014.

34. A1-Kazemi AFR. Effective method of teaching psychiatry to undergraduate medical students: the student perspective. Med Princ Pract. 2000;9(4):255-259.

35. SteinertY, Snell LS. Interactive lecturing: strategies for increasing participation in large group presentations. Med Teach. 1999;21(1):37-42. 


\section{Supplementary material}

Section 1: Regarding organization of lecture materials

1. The objectives of the lecture were clarified clearly in the beginning

2. Content of lecture related to the objectives of the lecture

3. A clear explanation of the technical terminology was given

4. Clear, relevant examples were used to illustrate the main ideas

5. The important points were emphasized periodically as the lecture proceeds

6. Made clear transitions between different segments of the lecture

7. Summarized the main points of the lecture at the end

8. Lecturing method was interactive, with adequate student participation

9. Recommended reading was advised for next lecture

Section 2: Regarding lecturer's voice and gesture

1. Uses microphone effectively

2. Speaks at a volume of ...

3. Speaks at a pace of ...

4. Varies rate, pitch, and force of voice for emphasis

5. Uses eye contact

6. Uses a variety of facial expressions

7. Moves purposefully

Section 3: Regarding use of visual aids/resources

1. Whether visual aids were used or not to enhance understanding of the lecture topic

2. Visual aids used were clear and easy to read

3. Visual aids were coordinated with verbal presentation

4. Lecture notes were provided

Section 4: Regarding fulfilling of the objectives of lecture class

1. Lecturer covered the points intended in the objectives

2. Subject matter is understood

3. Lecture topics were communicated effectively

4. Lecturer encouraged me to express ideas

5. Lecture stimulated my interest in the subject

6. Lecture was well-organized

7. Lecturing style made note taking difficult

Section 5: Regarding physical facilities of lecture hall

1. Physical facilities in this lecture hall are adequate for lecture

Section 6: Compared with other teaching/learning methods

1. Do you think that any other teaching methods could better deliver this topic?

2. If yes, please name the method or methods.

Open ended question:

1. Please suggest how we could improve this lecture further?

Figure SI Evaluation of lectures: student's perspectives.

Advances in Medical Education and Practice

\section{Publish your work in this journal}

Advances in Medical Education and Practice is an international, peerreviewed, open access journal that aims to present and publish research on Medical Education covering medical, dental, nursing and allied health care professional education. The journal covers undergraduate education, postgraduate training and continuing medical education including emerging trends and innovative models linking education, research, and health care services. The manuscript management system is completely online and includes a very quick and fair peer-review system. Visit http://www.dovepress.com/testimonials.php to read real quotes from published authors.

Submit your manuscript here: http://www.dovepress.com/advances-in-medical-education-and-practice-journal 